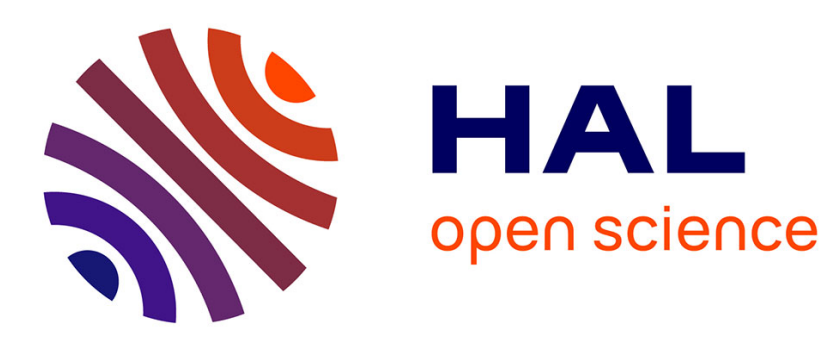

\title{
Effects of Cyclic Plastic Strain on Hydrogen Environment Assisted Cracking in High-Strength Steel
}

Flavien Vucko, Cédric Bosch, David Delafosse

\section{To cite this version:}

Flavien Vucko, Cédric Bosch, David Delafosse. Effects of Cyclic Plastic Strain on Hydrogen Environment Assisted Cracking in High-Strength Steel. International Hydrogen Conference (IHC 2012): Hydrogen-Materials Interactions, Sep 2012, Moran, WY, United States. Chap 38, 10.1115/1.860298_ch38. emse-01063865

\section{HAL Id: emse-01063865 \\ https://hal-emse.ccsd.cnrs.fr/emse-01063865}

Submitted on 14 Sep 2014

HAL is a multi-disciplinary open access archive for the deposit and dissemination of scientific research documents, whether they are published or not. The documents may come from teaching and research institutions in France or abroad, or from public or private research centers.
L'archive ouverte pluridisciplinaire HAL, est destinée au dépôt et à la diffusion de documents scientifiques de niveau recherche, publiés ou non, émanant des établissements d'enseignement et de recherche français ou étrangers, des laboratoires publics ou privés. 


\title{
Effects of cyclic plastic strain on hydrogen environment assisted cracking in high-strength steel \\ Effets de la déformation plastique cyclique sur la fissuration assistée par I'hydrogène d'un acier à haute résistance
}

\author{
F. Vucko, C. Bosch, D. Delafosse \\ Ecole Nationale Supérieure des Mines, SMS-EMSE, CNRS: UMR 5307, LGF, 158 \\ cours Fauriel, 42023 Saint-Etienne, France
}

Chap 38 in : Proceedings International Hydrogen Conference (IHC 2012): Hydrogen-Materials Interactions, BP Somerday \& P Sofronis (eds), September 9-12 2012, Moran WY

Publ. ASME, ISBN : 9780791860298, DOI : 10.1115/1.860298_ch38

\section{Résumé}

Des essais de fatigue à amplitude de contrainte imposée ont été réalisés sur des éprouvettes microentaillées en acier à haute limite d'élasticité S690QL (EN 10137-2). Ces essais ont été effectués à l'air et en solution saline sous protection cathodique. Les éprouvettes ont été modélisées et leur comportement mécanique a été simulé par des calculs par éléments finis. Une loi d'écrouissage non-linéaire combinant une loi d'écrouissage isotrope et une autre cinématique a été utilisée. Ce modèle est capable de reproduire l'adoucissement cyclique et l'effet Rochet caractéristique du matériau. Les champs de contrainte et de déformation plastique ont été calculés dans la zone proche de l'entaille. Les résultats montrent une forte dépendance de l'amorçage de la fissure avec l'accumulation de déformation plastique. Les mécanismes de fragilisation par l'hydrogène sont alors discutés par rapport au réarrangement des structures de dislocations en fatigue.

\section{Abstract}

Cyclic loading tests were performed on micro-notched samples of high-strength steel S690QL (standard EN 10137-2) in air and under cathodic polarization in a saline solution. These specimens were modeled and their behavior simulated by finite elements calculations with a combined nonlinear isotropickinematic hardening constitutive law. This model can simulate cyclic softening and ratcheting effect of the high-strength steel. Stress and strain fields in the vicinity of the notch-tip were calculated. Results show a strong dependence of the crack initiation with plastic strain accumulation. Hydrogen assisted cracking mechanism is discussed based on arrangements of dislocations structures. 


\section{Table of content}

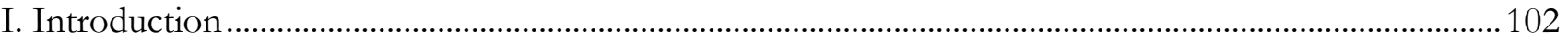

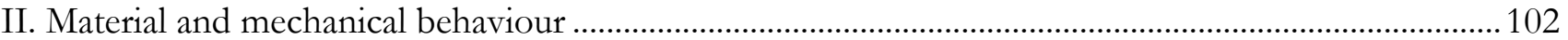

III. Hydrogen Assisted cracking tests ....................................................................................................... 104

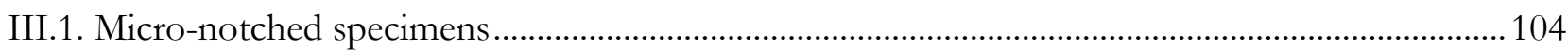

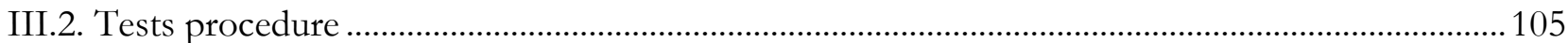

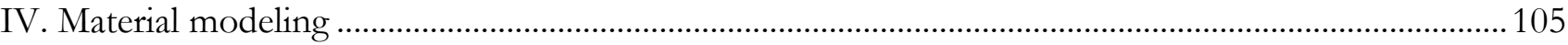

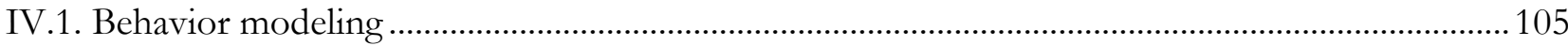

IV.2. Calibration and validation of the model ............................................................................................ 106

IV.3. Simulation of initiation stage of cracking tests .............................................................................. 106

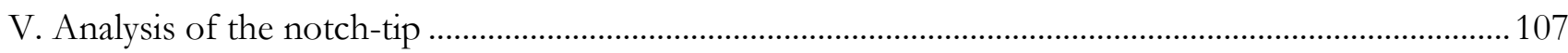

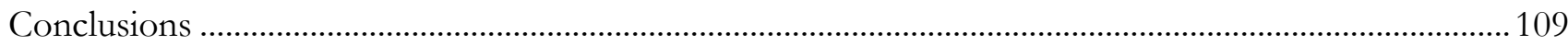




\section{Introduction}

The interest in the use of high-strength steels as structural materials is both environmental and economic since it allows lightening the weight of structures. Nevertheless, these materials are very sensitive to hydrogen effect which could be responsible of severe damages in the presence of hydrogen sources. Many studies have shown that this sensitivity increases with the mechanical strength of steels [1]. Furthermore in hydrogenating conditions, tensile properties and fatigue behavior are modified [2-5]. The sensitivity to surface defects is also affected by hydrogen [6]. Indeed both effect of hydrostatic stress gradient on the chemical potential of hydrogen and localization of plastic strain at defect-tips promote the increase of hydrogen content and hydrogen-plasticity interactions.

In this paper, we present an experimental method and simulation procedure to investigate and quantify the role of plastic strain, stress and hydrogen trapping on the mechanisms of initiation and propagation of cracking of quenched and tempered martensitic steel in a hydrogenating environment. Mechanical tests at constant and cyclic loading were performed on micro-notched specimens under cathodic polarization in de-aerated saline solution. The strain hardening (or softening) rate at notch-tip was fitted by controlling the maximum stress, the stress ratio and the number of cycles applied. Specimens were instrumented to monitor crack initiation and crack growth rate with a DCPD (Direct Current Potential Drop) method. Added to these tests, numerical simulations on finite elements code ZeBuLon have modeled the mechanical behavior of the steel at the micro-notch root. Stress and strain fields in the vicinity of notch-tip have been determined.

This paper is divided in four parts. In the first one, we present the material and its mechanical behavior. The second part deals with the procedure for hydrogen assisted cracking (HAC) tests, and explains the role of micro-notch on specimens. Then, the combined nonlinear isotropic-kinematic hardening material constitutive law used to model the behavior of the steel is presented in detail. Finally, experimental results on crack initiation are analyzed and discussed based on FE calculations of stress and plastic strain fields at notch-tip.

\section{Material and mechanical behaviour}

The material of the study is a high-strength steel S690QL (EN 10137-2, ASTM A514). It presents a tempered martensitic microstructure (see Fig. 1) consisting of laths of about $200 \mathrm{~nm}$ wide gathered in blocks and packets included in prior austenite grain. Cementite along lath boundaries was observed. The austenitizing temperature is $920^{\circ} \mathrm{C}$. The duration and temperature of the tempering are two hours at $550^{\circ} \mathrm{C}$. Prior austenite grain size is ranging from 10 to $20 \mu \mathrm{m}$. No retained austenite has been detected by X-Ray analysis. 


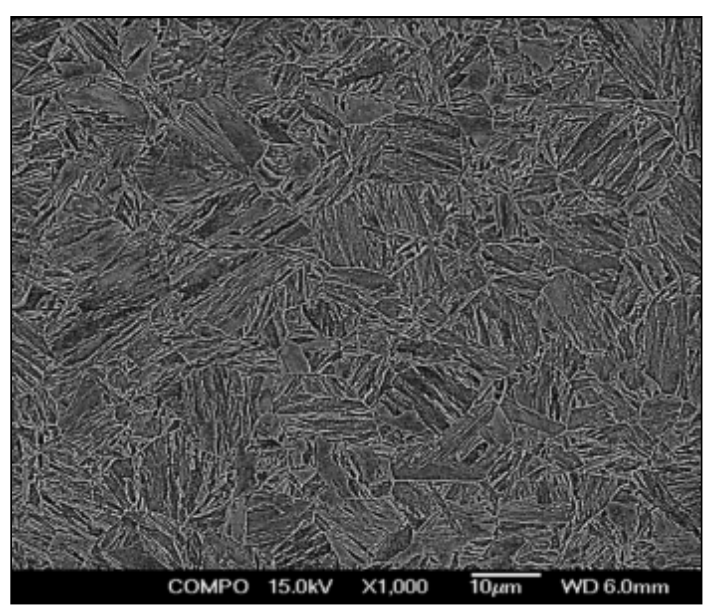

Fig. 1: SEM observation of the microstructure of S690QT steel

Yield stress, ultimate tensile stress and elongation are respectively $726 \mathrm{MPa}, 900 \mathrm{MPa}$ and $21.8 \%$. This steel presents a typical cyclic softening under fatigue cycling as shown in Fig. 2a. If cumulative plastic strain is defined as the accumulation of plastic strain whatever the direction of loading (here twice the number of cycle time the plastic strain amplitude), the softening can be divided in two stages (see Fig. 2b): a strong softening stage up to a cumulative plastic strain value of about 2 followed by a weak softening corresponding to a pseudo stability stage.
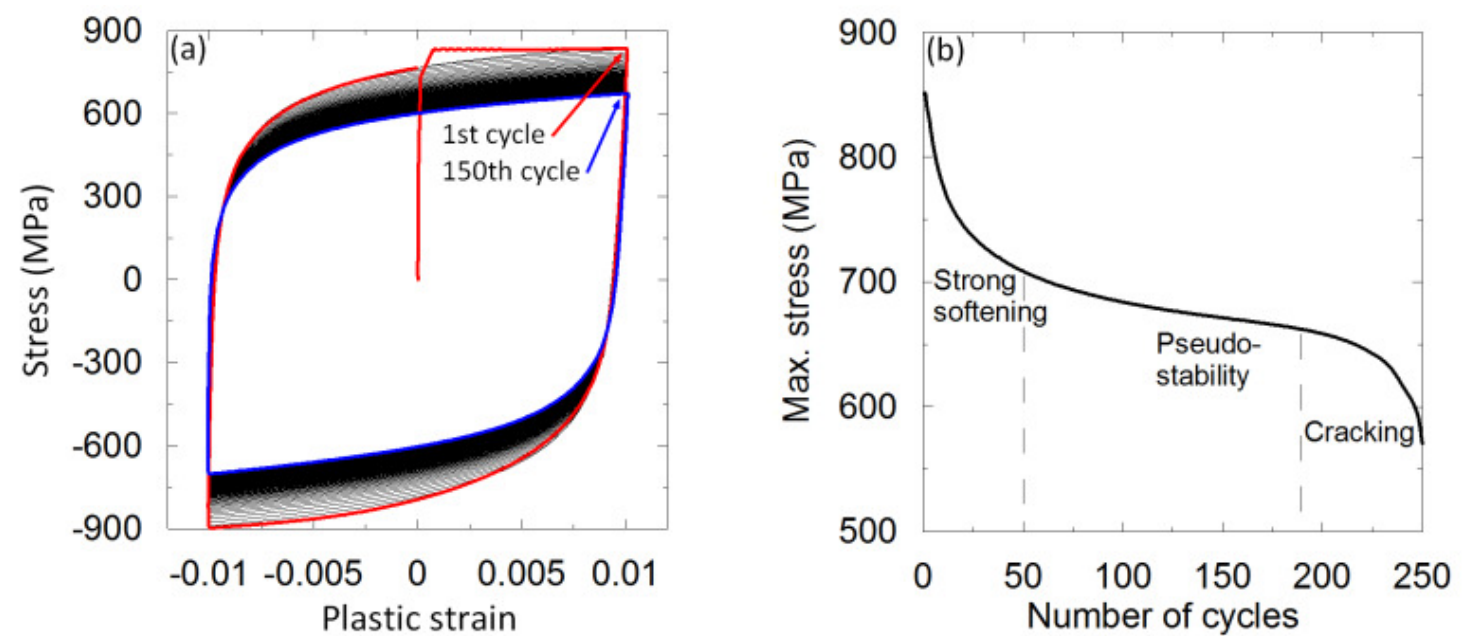

Fig. 2: (a) Hysteresis loops under fatigue loading (plastic strain amplitude of $2 \%$ at plastic strain rate of $5 \times 10^{-4}$ $s^{-1}$ ), (b) Maximal stress vs. number of cycles

Cyclic softening is controlled by the microstructure of the material [7-9]. During cyclic loading, density of dislocations decreases inside subgrains and the size of these subgrains can increase with plastic strain accumulation. 


\section{Hydrogen Assisted cracking tests}

\section{III.1. Micro-notched specimens}

HAC tests have been performed on micro-notched specimens. Notches were machined with a precision saw wire in order to avoid strain hardening. Notch radius is $40 \mu \mathrm{m}$ and depth is about $300 \mu \mathrm{m}$. This specific geometry of specimens has some interesting advantages. First of all, a notch provides a plastic zone that might concentrate hydrogen-plastic strain interactions. As a result, a single crack initiates on the notch-tip and so cracking can be monitored by a DCPD method to determine crack initiation and brittle crack growth rate, as used in this study (see Fig. 3 as an example of an in situ crack monitoring). Moreover, complex but controlled stress and strain fields can be developed on the notch-tip with simple loadings. Thanks to tensile-tensile fatigue tests with different load ratios $\mathrm{R}$, plastic strain can be accumulated on the notch-tip (see Fig. 4).

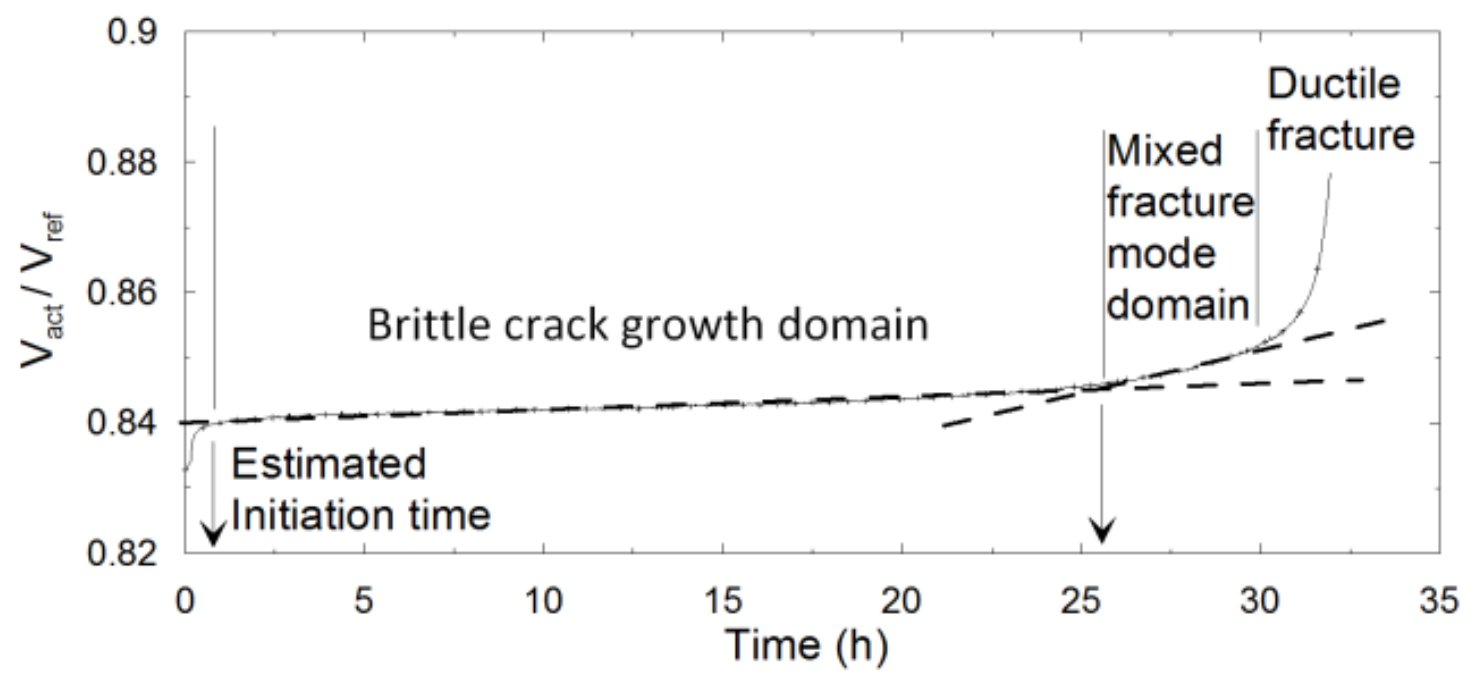

Fig. 3: In situ monitoring of cracking by DCPD method

No direct measurement of the level of stress and strain on the notch-tip can be made. Some simulations have to be developed to estimate these parameters. This modeling is discussed in the next part.

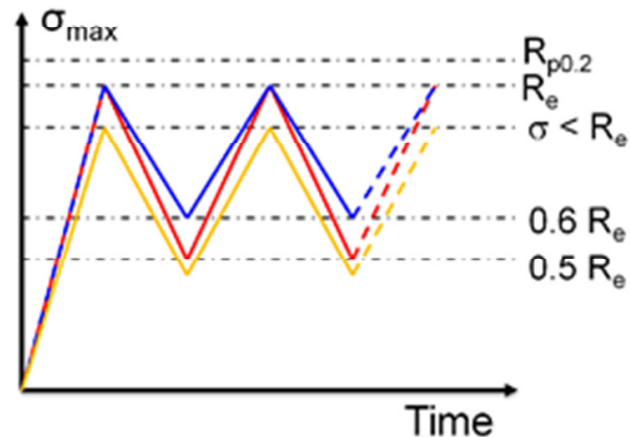

(a)

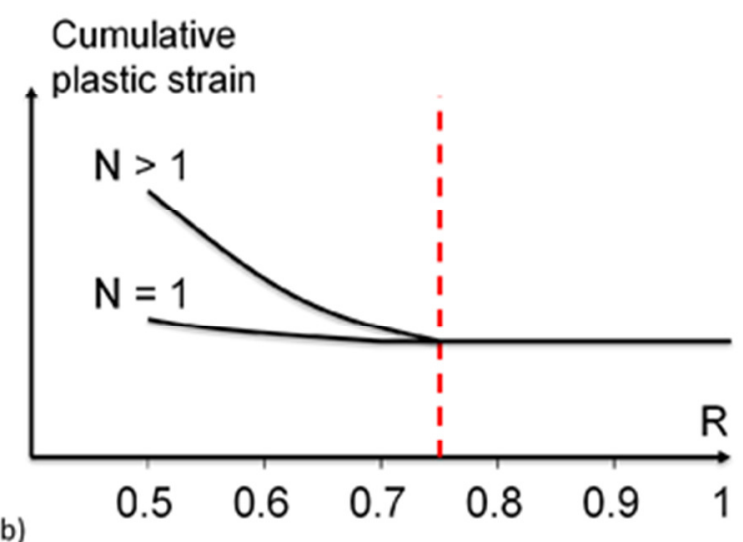

(b)

Fig. 4: (a) Tensile-tensile fatigue loading, (b) notch-tip response to tensile-tensile solicitations (experimental and simulation results) 


\section{III.2. Tests procedure}

Specimens are hydrogen charged by cathodic polarization in 30 g. $\mathrm{L}^{-1} \mathrm{NaCl}$ solution at $-1200 \mathrm{mV} / \mathrm{SCE}$. The solution was de-aerated and buffered at $\mathrm{pH} 4.5$ by bubbling in a gas mixture of nitrogen with $7 \%$ of carbon dioxide. The charging process was applied 12 hours before the mechanical loading and maintained throughout tests.

Levels of plastic strain and strain softening are controlled using tensile-tensile tests as discussed earlier and represented in Fig. 4. The remote stress value varies from 88 to $95 \%$ of the yield strength and load ratios from 0.5 to 0.8 . Frequency has been chosen equal to $10^{-3} \mathrm{~Hz}$. These tests lead to a gradual cyclic softening where accumulated plastic strain at micro-notch-tip depends on load ratio and number of cycles.

\section{Material modeling}

\section{IV.1. Behavior modeling}

Many constitutive laws have been developed to model mechanical behavior of metals. Isotropic and kinematic laws derive from thermodynamical formulation $[10,11]$. Combined laws were then developed $[12,13]$ to allow description of phenomena as Bauschinger effect, ratcheting effect and cyclic softening/hardening which occur around the notch. This kind of law is necessary to describe accurately the behavior of the steel.

Two hardening variables are used to describe this model. The backstress tensor $\mathrm{X}$ is the kinematic variable and the thermodynamic force $\mathrm{R}$ is the scalar isotropic variable. From a mechanical point of view, kinematic hardening is the displacement of the center of the yield surface and isotropic hardening is the expansion/contraction of this surface.

Their evolution equations are:

$\underline{\underline{\dot{X}}}=\sum_{i} \underline{\underline{\dot{X}}}_{\mathrm{i}}$ with $\underline{\underline{\dot{X}}}_{\mathrm{i}}=c_{i} \dot{\varepsilon}^{p}-\gamma_{i} \underline{\underline{X}}_{i} \dot{p}$

Eq.1

$\dot{R}=b(Q-R) d p$

Eq.2

where $c_{i}, \gamma_{i}, b, Q$ are material dependent constants. One way to take into account the isotropic hardening is to introduce a function of the cumulative plastic strain $c_{i}(p)$ in the kinematic variable $X$ :

$\underline{\underline{\dot{X}}}_{i}=c_{i}(p) \dot{\varepsilon}^{p}-\gamma_{i} \underline{\underline{X}}_{i} \dot{p}$ with $c_{i}(p)=\frac{C_{i}}{\sigma^{0}(p)}$

Eq.3

$\mathrm{c}_{\mathrm{i}}$ is a material dependent constant and $\sigma_{0}(\mathrm{p})$ is an exponential law which modeled the isotropic hardening:

$\sigma^{0}(p)=\sigma_{y}+Q\left(1-e^{-b p}\right)$

Eq.4 
where $\sigma_{\mathrm{y}}$ is the strain-independent yield stress; Q is the asymptotic value when the saturated stage is reached; $b$ is the rate at which the stage is attained.

This model has been implemented in the finite elements code ZeBuLon.

\section{IV.2. Calibration and validation of the model}

Model parameters identification is based on low cycle fatigue tests at different plastic strain amplitude (from 0.4 to $4 \%$ ) and at constant strain rate $\left(5 \times 10^{-4} \mathrm{~s}^{-1}\right)$. Using graphical optimization, the model has been fitted to experimental data. An initial work hardened state has been considered through an initial backstress tensor.

A simulated low cycle fatigue test at $1 \%$ of plastic strain amplitude is presented in Fig. 5a and results are compared to experimental data in Fig. 5b. The model follows quite well the cyclic softening of the material and shapes of hysteresis loops are in accordance with experimental observations.
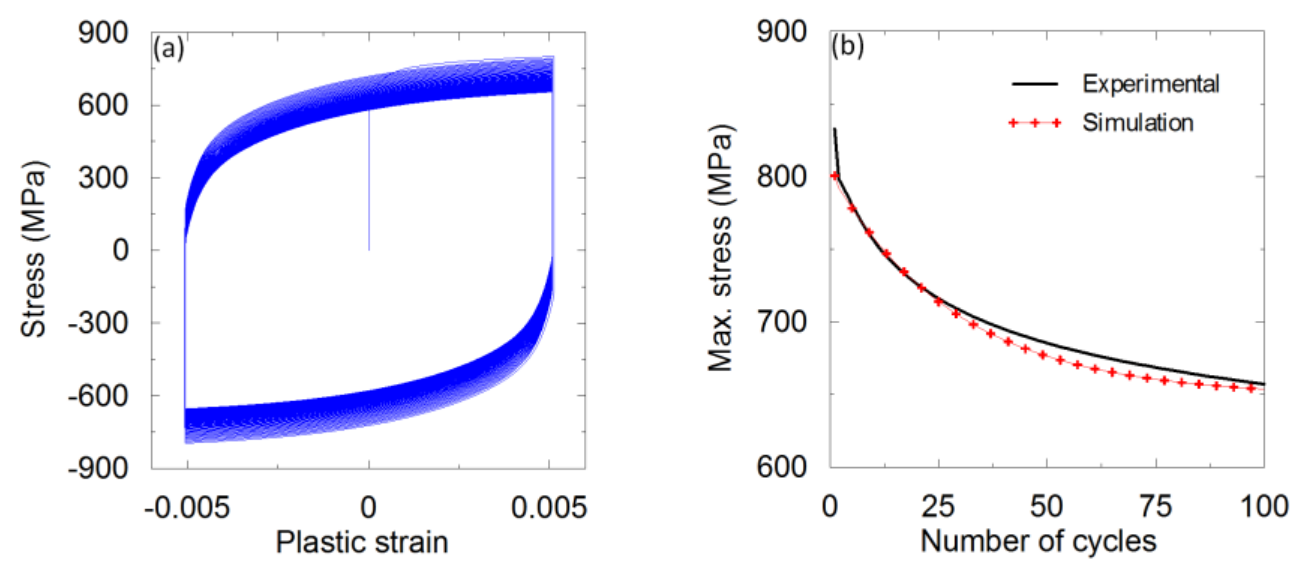

Fig. 5: (a) Simulated hysteresis loops for plastic strain amplitude of 1\%, (b) maximal stress vs. number of cycles from simulation and experimental data.

\section{IV.3. Simulation of initiation stage of cracking tests}

Tensile-tensile fatigue tests on notched specimens have been simulated on FE code ZeBuLon. The mesh around the notch and the integration point used for stress and strain calculations is presented in Fig. 6 a.

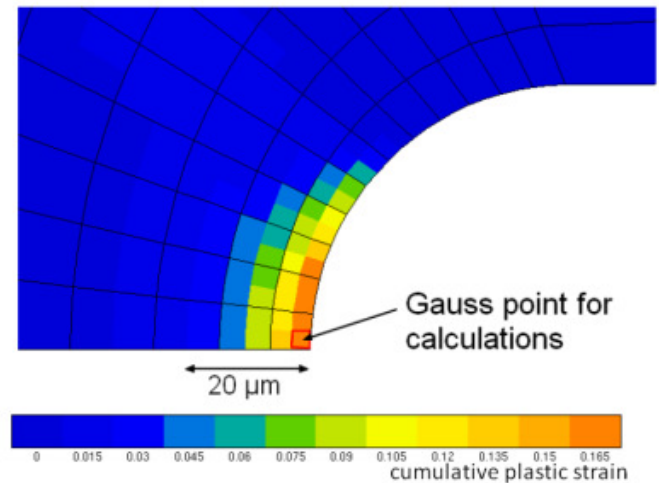

(a)

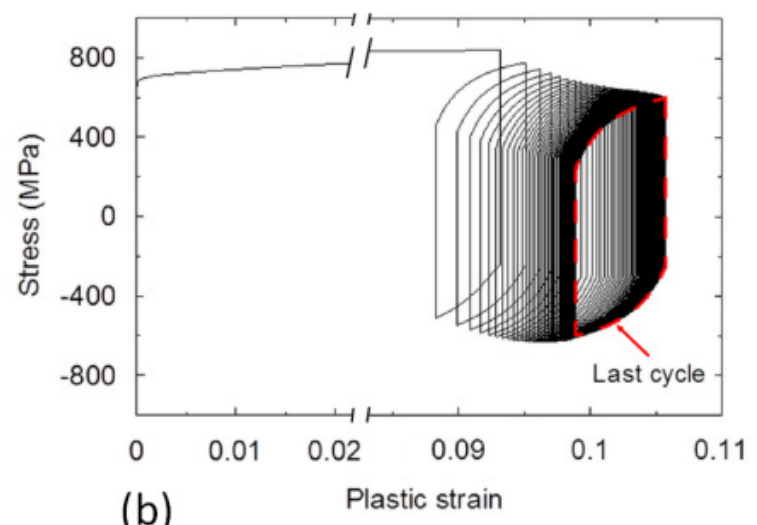

(b)

Fig. 6: (a) Mesh around the notch, (b) notch-tip response to tensile-tensile cycling (simulation for $R=0.5$ and $\left.\sigma_{\max }=88 \% Y S\right)$ 
Stress vs. plastic strain on the notch-tip is plotted in Fig. 6b. The notch exhibits an asymmetric loading during the first cycles which leads to a ratcheting effect on the plastic strain. Accumulation of plastic strain is responsible of a strong softening till a saturation stage. The softening is related to relaxation of the mean stress down to zero and intrinsic softening of the material with cumulative plastic strain.

\section{Analysis of the notch-tip}

Crack initiation times for tensile-tensile tests performed in hydrogenating environment are obtained with DCPD method and reported in Fig. 7 as a function of load ratios. The maximum initial stresses on the notch-tip, $\sigma_{\text {notch-tip }}$, calculated by FE are also reported on the graph. They are ranged from 831 to 843 $\mathrm{MPa}$.

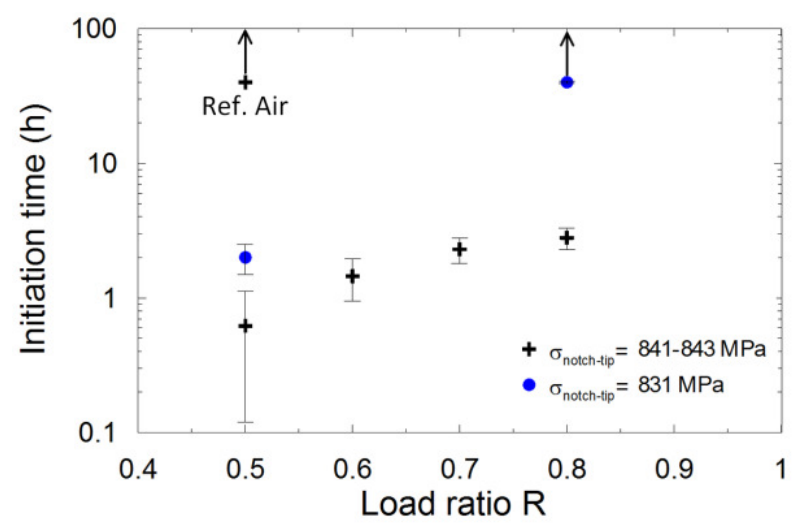

Fig. 7: Initiation times of tensile-tensile fatigue tests in hydrogenating conditions (except for reference in air, black cross in the top left-hand corner)

The crack initiation time clearly depends on stress and load ratio applied. For a given maximum stress applied, the greater is the load ratio the longer is the initiation time. While for a given load ratio, increasing applied stress decreases the initiation time. For the higher load ratio $(\mathrm{R}=0.8)$, no crack initiation occurred at the lowest $\sigma_{\text {notch-tip }}$. Similarly, test performed in air in the harshest mechanical conditions has no crack.

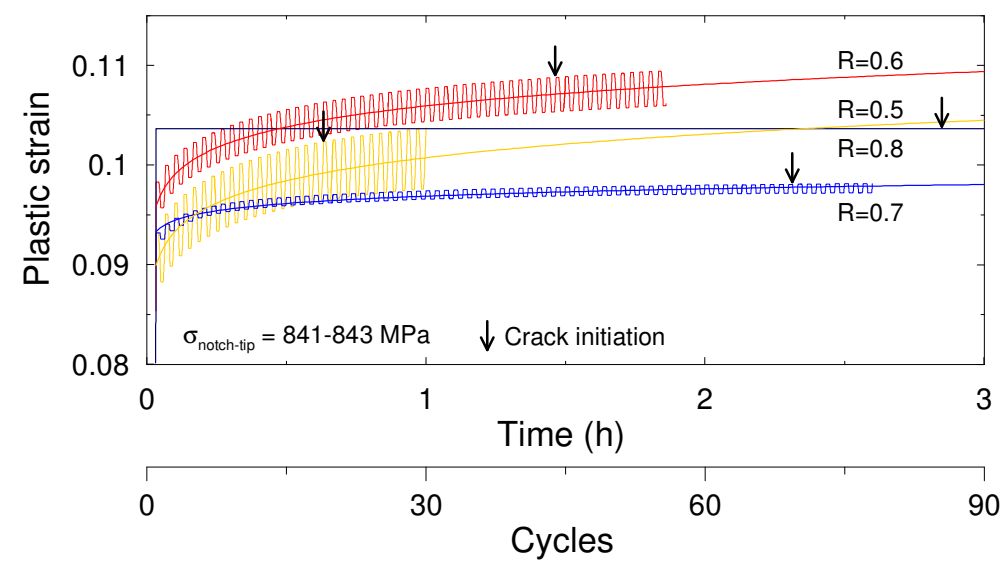

Fig. 8: Plastic strain vs. number of cycles at different load ratios 
Investigations with the FE model show that for a given maximum stress applied, the greater is the load ratio the smaller is the swept amplitude of stress and plastic strain at each cycle (see Fig. 8 for plastic strain). Consequently, the cumulative plastic strain is more important for low load ratios. Increasing load ratio up to 0.8 reduces the strain amplitude to zero and no more plastic strain occurs after the first quarter of cycle.

The evolution of the maximum stress at the notch-tip during first cycles is represented in Fig. 9. For load ratios smaller than 0.8 , cyclic softening occurs in three stages: an initial strong softening with a rate identical for all the conditions of loading explored; a second stage where the rate decreases; and a saturation stage with a small and constant rate of softening.

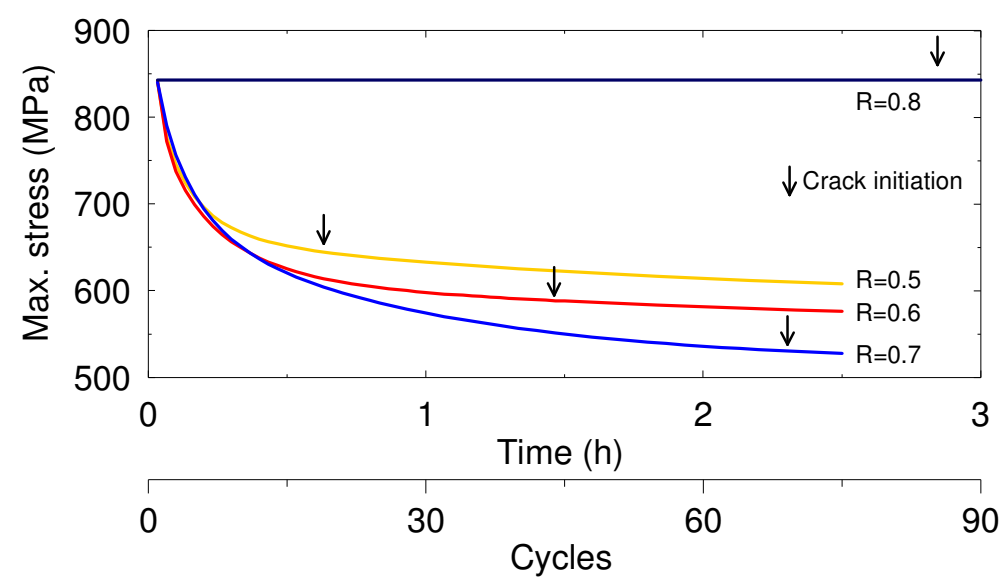

Fig. 9: Evolution of maximum stress at different load ratios

At $R=0.5$, the saturation stage begins at about 15 cycles, much earlier than at 0.6 and 0.7 . It indicates that increasing the stress amplitude, and so the plastic strain amplitude, contributes to reach more quickly the saturation stage. Plastic strain accommodation to the mechanical loading is faster. The maximum stress at notch-tip on the saturation stage depends on the level of initial mean stress. At high R-ratios, the mean stress is important which induces a high cyclic softening. For smaller R-ratios, the initial mean stress is lower so cyclic softening is weaker. Crack initiations (see arrows in Fig. 9) occur at the beginning of the saturation stage, so crack initiation times seem to be shorter as maximum stress at notch-tip is high. Nevertheless, test at $\mathrm{R}=0.8$ shows this is not the only factor of HAC damage.

FE calculations for tests loaded at $\sigma_{\text {notch-tip }}=831 \mathrm{MPa}$ present similar results: no accumulation of plastic strain at $\mathrm{R}=0.8$ whereas plastic strain occurs at each cycle at $\mathrm{R}=0.5$ and so cumulative plastic strain increases with time (see Fig. 10). Compared to previous results crack initiation is delayed by a factor of three at least at $\mathrm{R}=0.5$ but no crack has been detected at $\mathrm{R}=0.8$. In this last condition, stress applied seems to be too low to initiate a crack. Consequently HAC at $\mathrm{R}=0.5$ can be attributed to plastic strain accumulation. 


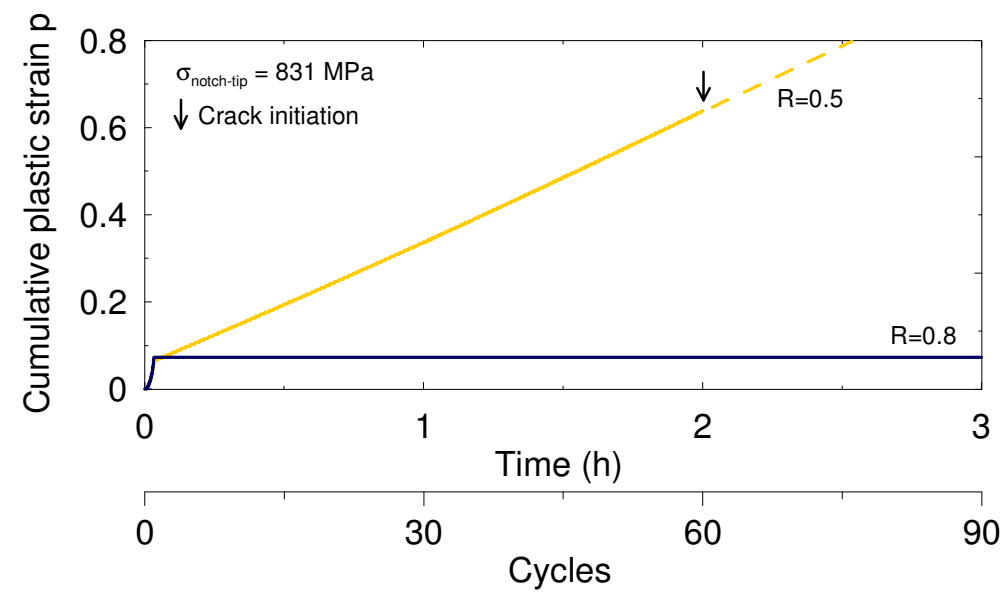

Fig. 10: Accumulation of plastic strain at lower maximum stress

\section{Conclusions}

A local approach of fracture method has been developed to investigate sensitivity to HAC of a high strength steel S690QT. Cyclic behavior has been modeled by FE using a combined nonlinear isotropickinematic hardening constitutive law. Calculations of local mechanical variables were used to analyze HAC tests.

Crack initiation time depended on both cumulative plastic strain and current value of stress at notch-tip. At load ratios below 0.8 , plastic strain occurred at each cycle which contributes to decrease initiation time even when local stress is decreased. Moreover, when stress is not high enough to initiate a crack, accumulation of plastic strain and modifications of microstructure associated can trigger the cracking conditions. 


\section{References}

[1] Hirth, J. P., 1980, "Effects of hydrogen on the properties of iron and steel", Metall Mater Trans A, 11, pp. 861-890

[2] Brass, A.-M., Chêne, J., 2006, "Hydrogen uptake in 316L stainless steel: Consequences on the tensile properties", Corros Sci, 48, pp. 3222-3242

[3] Hardie, D., Charles, E. A., Lopez, A. H., 2006, "Hydrogen embrittlement of high strength pipeline steels", Corros Sci, 48, pp. 4378-4385

[4] Huneau, B., Mendez, J., 2006, "Evaluation of environmental effects on fatigue crack growth behaviour of a high strength steel in a saline solution with cathodic protection", Int J Fatigue, 28, pp. 124-131

[5] Murakami, Y., Matsuoka, S., 2010, "Effect of hydrogen on fatigue crack growth of metals", Eng Fract Mech, 77, pp. 1926-1940

[6] Sofronis, P., McMeeking, R. M., 1989, "Numerical analysis of hydrogen transport near a blunting crack tip", J Mech Phys Solids, 37, pp. 317-350

[7] Chai, H. F., Laird C., 1987, "Mechanisms of cyclic softening and cyclic creep in low carbon steel”, Mater Sci Eng, 93, pp. 159-174

[8] Fournier, B., et al., 2009, "Microstructural evolutions and cyclic softening of $9 \% \mathrm{Cr}$ martensitic steels", J Nucl Mater, 386-388, p. 71-74

[9] Giordana, M. F. et al., 2012, "Microstructure evolution during cyclic tests on EUROFER 97 at room temperature. TEM observation and modelling", Mater Sci Eng A, 550, pp. 103-111

[10] Prager, W., 1956, "A new method of analyzing stresses and strains in work-hardening plastic solids", ASME J Appl Mech, 23, pp. 493-

[11] Ziegler, H., 1959, “A modification of Prager's hardening rule”, Quart Appl Math, 17, pp. 55

[12] Armstrong, P. J., Frederick, C. O., 1966, "A mathematical representation of the multiaxial Bauschinger effect", Materials at high temperature, 24, pp. 1-26

[13] Chaboche, J.-L., 1991, "On some modifications of kinematic hardening to improve the description of ratcheting effect", Int J Plasticity, 7, pp. 661-678

[14] Kim, D. W., Kim S. S., 2012, “Contribution of microstructure and slip system to cyclic softening of 9 wt.\%Cr steel”, Inter J Fatigue, 36, pp. 24-29

[15] Nagumo, M., Sekiguchi, S., Hayashi, H., Takai, K., 2003, "Enhanced susceptibility to delayed fracture in pre-fatigue martensitic steel”, Mater Sci Eng A, 344, pp. 86-91. 